\title{
Poverty and fertility: Evidence and agenda
}

\author{
Sajeda Amin \\ Population Council \\ John B. Casterline \\ Laura Spess
}

Follow this and additional works at: https://knowledgecommons.popcouncil.org/departments_sbsr-pgy

Part of the Demography, Population, and Ecology Commons, Family, Life Course, and Society Commons, Inequality and Stratification Commons, and the International Public Health Commons How does access to this work benefit you? Let us know!

\section{Recommended Citation}

Amin, Sajeda, John B. Casterline, and Laura Spess. 2007. "Poverty and fertility: Evidence and agenda," Poverty, Gender, and Youth Working Paper no. 4. New York: Population Council. 


\title{
POVERTY, GENDER, AND YOUTH
}

\section{Poverty and Fertility: Evidence and Agenda}

\author{
Sajeda Amin, John B. Casterline, and Laura Spess
}




\section{(2) Population Council}

One Dag Hammarskjold Plaza

New York, New York 10017 USA

www.popcouncil.org

pubinfo@popcouncil.org

Our new name Beginning with the first number of 2007, Policy Research Division working papers are now called Poverty, Gender, and Youth working papers. For information on papers in both series, including those that are available for downloading in PDF format, see www.popcouncil.org/publications/wp/index.html

This material may not be reproduced without written permission from the authors.

ISSN: $1554-8538$

(C) 2007 The Population Council, Inc. 


\title{
Poverty and Fertility: Evidence and Agenda
}

\author{
Sajeda Amin \\ John B. Casterline \\ Laura Spess
}

Sajeda Amin is Senior Associate, Poverty, Gender, and Youth Program, Population Council, New York. John B. Casterline is Professor of Sociology, Ohio State University. Laura Spess is a graduate student, Department of Geography, Pennsylvania State University.

An earlier version of this paper was presented at the Annual Meeting of the Population Association of America, Philadelphia, 31 March-2 April 2005. Support was provided by grants from the Hewlett Foundation and the Mellon Foundation to the Population Council. 


\begin{abstract}
This paper explores how poverty affects childbearing patterns in the contemporary developing world. In considering the association between poverty and fertility, we explore one measure of economic status, household asset holdings, in Demographic and Health Surveys conducted in 51 countries since 1990. The results show that the association between poverty and fertility differs according to the measure of fertility considered. We conclude there is much to be gained from distinguishing between the impact of poverty on fertility aspirations and the implementation of those aspirations. Differentials in fertility aspirations are less common and smaller in magnitude than differentials in the implementation of aspirations. Fertility aspirations reflect strategizing about fertility that is embedded in broader strategizing about the future well-being of individuals and households. For multiple reasons, this strategizing need not result in a sharp and monotonic association between fertility aspirations and household economic status. In exploring the literature on poverty, we find a growing interest in the role of social capital and how it contributes to the maintenance or attenuation of poverty. The poverty literature could benefit from the considerable body of work on fertility that has articulated a central role of social capital. Moreover, our understanding of the association between poverty and fertility would be strengthened by more attention to the role of social capital.
\end{abstract}


After several decades of relative neglect, economic status - and, specifically, povertyhas become a dominant concern in population research on developing countries. Of particular interest is economic status as both cause and consequence of demographic variables at the macro and micro level. The most active streams of work have examined (i) macro-level impacts of demographic change on economic growth and poverty (e.g., the "demographic gift") (Eastwood and Lipton 2001; Kelley and Schmidt 2001; Mason 2001) and (ii) micro-level effects of household economic status on demographic variables (fertility, health/mortality, geographic mobility) (Merrick 2002; Montgomery and Hewett 2005). Work also continues at a lower level of intensity on the reverse causality, namely (iii) micro-level effects of demographic variables (fertility, health/mortality) on economic well-being and poverty (Greene and Merrick 2005; Bernstein 2006).

Our principal aim here is to enrich the second stream of work, on micro-level effects of household economic status on demographic variables. In pursuit of this aim, the paper has two components: first, with DHS data we investigate the association between household wealth and two indicators of fertility attitudes and behaviors; second, using these empirical findings as a springboard, we argue that research on the association between household economic status and fertility would be strengthened by richer conceptualization of the key concepts, economic status in particular.

We adhere to Amartya Sen's view that poverty is more than a simple lack of income. Poverty should be regarded more broadly as the lack of capabilities of men and women to function at some minimal level, as they see fit. These capabilities include the ability to be fed, clothed, and have shelter, all closely related to income but extended to notions of functioning that pertain to good health, education, and effective civic participation. This notion of poverty derives from a view that "expanding the freedoms that people enjoy" is both a means and an end of development (Sen 1999; Deaton 2006). This notion of poverty highlights an aspirational and subjective dimension ("as they see fit") in addition to the objective dimension of the ability to achieve those aspirations. Although aspirations and some aspects of abilities are relative, the ultimate concern is poverty-as-deprivation in some absolute sense that limits individuals' abilities to function with dignity (Sen 1983).

Measuring poverty from this perspective is extraordinarily difficult, and with a few exceptions ${ }^{1}$ most attempts, particularly in research that assesses variation across countries and over time, fall far short of this expansive notion of poverty and focus on aspects closely related to income (Deaton 2006). And, indeed, the measure of poverty used in the empirical analysis presented here also corresponds closely to income-related poverty. We discuss the limitations of an income measure of poverty for the purpose of understanding the determination of fertility, and we consider research approaches that can strengthen our understanding of a broader notion of poverty.

\section{HouSEHOLd ECONOMIC STATUS AND FERTILITY}

The association between the household economy and reproduction is at the core of Malthusian theory, and accordingly there has been extensive investigation of the association between economic indicators and fertility in historical populations (e.g., Galloway 1988; Lee and Wang 1999; Bengtsson and Dribe 2006). This relationship is also a pivotal one for Gary 
Becker and other economists who have produced a rich theoretical and empirical literature during the past four decades (Sanderson 1976; Becker and Lewis 1973; Easterlin 1975). One strand of this literature examines the impact of reproduction on economic status, at both the micro level (Lloyd 1994; Ahlburg 1998) and the macro level (Mason 2001). A fundamental issue, by no means fully resolved, is the contribution of fertility to the generation and maintenance of societal inequality (Lam 1986; Kremer and Chen 1999; Williamson 2001). We acknowledge that our research on the effects of economic status on fertility ignores this reverse causality, namely the effects of childbearing on household economic status. To the extent these effects occur intragenerationally, our estimates of the effects of economic status on fertility are biased. The main focus of the literature, however, is on intergenerational effects of fertility on socioeconomic status.

Our investigation of the effects of household economic status on fertility begins with the premise that observed fertility patterns reflect both fertility aspirations ${ }^{2}$ and success in implementing those aspirations (i.e., via contraception or induced abortion). This is a standard distinction in research on fertility: demand for children and deliberate fertility regulation; or, in Easterlin's (1975) synthesis framework, motivation to regulate fertility and the costs of regulation. While this distinction is familiar, it has not effectively informed recent considerations of how household economic status (and poverty in particular) might affect fertility.

In most settings the costs of fertility regulation include financial costs (Hermalin 1983), hence it is natural to hypothesize that greater household economic resources will increase the success in implementing fertility aspirations. Also in most settings the accessibility and quality of family planning services vary by community wealth (Grady et al. 1993; Stephenson and Tsui 2002), and this is a further reason why poorer households may be less successful in implementing their fertility aspirations (Montgomery and Hewett 2005). Here theory about poverty and fertility closely parallels theory about poverty and health and mortality (Pebley, Goldman, and Rodríquez 1996; Jahn et al. 1998). To be sure, in neither case can the effects of poverty (on fertility regulation, on health production) be reduced simply to expressions of resource deprivation (at the household level, and corresponding deficits at the community level). Other factors - knowledge, attitudes - that are in part a function of economic status may also contribute to the generation of observed differentials (Panel on Urban Population Dynamics 2003).

The relationship between household economic resources and fertility aspirations is more complex. First, a lack of material resources is but one of the relevant aspects of economic status: other forms of deprivation attendant on material deprivation can also enter into the determination of fertility aspirations. The penultimate section of this paper discusses the multiple dimensions of household poverty/wealth and how this bears on the empirical association between household economics and fertility. Our conclusion is that demographic research would be strengthened if it incorporated the more variegated understanding of poverty that is now accepted in the economic development literature.

Second, even when attention is confined to household income and wealth, hypothesized effects on fertility aspirations are multiple and contradictory. Consider, for example, the expected impact of income on fertility. Following standard micro-economic theory in the Becker tradition (Becker 1991), Schultz (2006) posits that the impact of income differs 
depending on the source of income. Variation in income that is due to variation in the value of women's time (e.g., increases in their wage-earning potential, perhaps resulting from their increased schooling) should be inversely related to fertility demand, because of a positive association between income and the value of women's time. Women's income may also dampen fertility demand by increasing women's bargaining power in the household and, among other outcomes, shifting the intrahousehold allocation of resources toward children, thereby increasing the cost of children. In contrast, variation in income that is due to variation in the returns to physical assets - business assets, land - should be positively related to fertility aspirations, because this source of variation in income is not associated with the opportunity cost of children. Indeed, children's labor value to their parents may be greater in households that possess more physical assets.

Children become more costly to the extent that parents have relatively high expectations for child quality, as represented most notably in schooling. Mainstream micro-economic theory posits that increases in income are ordinarily, but not necessarily, associated with an increase in per child investment (money and time) by parents (Becker and Lewis 1973). If the increase in per child investment exceeds the increase in household income, as theory suggests is often the case (and as empirical experience indicates as well; Becker et al. 1990), then higher income will on balance lead to reduced demand for children. But the precise quantitative tradeoff between quantity and quality of children is not easily determined: it is heavily conditioned by contextual factors such as kinship systems (and their norms about intergenerational relations and the allocation of resources among children) and the nature of the economy (in particular, the returns to human capital investment).

In short, mainstream micro-economic theory suggests that the observed relationship between household economic status and fertility aspirations in low-income societies will not be uniformly sharp and monotonic; rather the relationship is believed to vary across settings in its strength and even in its direction. To this complexity we add further social psychological considerations. We consider fertility aspirations as an expression of individuals' strategizing about childbearing in the context of their strategizing about a broader array of valued goals (economic, health, social). A desire to limit fertility (e.g., to two or three children) presumes, therefore, that (i) other valued goals have been articulated and, crucially, (ii) are regarded as achievable, and, further, that (iii) having fewer children is believed to improve the chances of achieving those goals. That is, this deliberation is in part a matter of confronting discrepancies between what individuals want and what they have, which Ray (2006) terms "the aspirations gap." Ray argues that either a small or a large aspirations gap can discourage actions to close the gap, the former because there is not much to gain and the latter because success seems unachievable.

Given the three-part conditionality in the previous paragraph, there is no reason to expect a simple and strong effect of household economic status (and, in particular, poverty) on fertility aspirations (viewing these as expressions of fertility strategizing). To illustrate, one can imagine settings in which the desire to limit fertility is higher among those in the middle economic strata and lower among both the wealthy and the poor. In this hypothetical setting, fertility aspirations in all strata reflect conscious strategizing that is heavily informed both by economic aspirations and by assessments of the feasibility of achieving those aspirations. Yet the wealthy and the poor arrive at roughly the same decision for radically different reasons: the 
wealthy are better able to afford children (although of course in moderation), while the poor depend on children (again, in moderate numbers) for their labor contribution, old-age security, and other risk insurance purposes (Kabeer 2001). For neither group are a small number of children a step toward closing a portion of their "aspirations gap." Hence, fertility aspirations would show a weak association with household economic status, despite the fact that in all economic strata these aspirations are thoroughly informed by forward-looking strategizing about how to achieve economic (and other) goals.

This is but one hypothetical setting. We can imagine contrasting settings in which-also as an outcome of strategizing about how to achieve economic goals (and how to avoid economic distress) - fertility aspirations align closely with economic status, either positively or inversely. An inverse relationship might be a reflection of the poor placing considerable value on childbearing as part of a broader strategy for dealing with environments of risk, and/or it might reflect a lack of belief by the poor that severely limiting their childbearing will significantly improve their economic prospects; in short, their aspirations gap is so wide that actions such as restricting childbearing seem pointless. The wealthy, in contrast, may want to limit themselves to a few children in order to preserve family wealth intergenerationally (less dilution through inheritance) and to take advantage of emerging economic opportunities (via better-educated children and investments of financial capital in economic ventures).

The general point is that if one embeds childbearing in broader household-level strategies to deal with economic threats and opportunities, both ex ante and ex post, then the expected association between economic status and fertility aspirations is by no means sharp or even monotonic.

From this discussion we derive the following expectations about the direction and strength of differentials in reproductive attitudes and behaviors according to household economic status:

- Success in implementing fertility aspirations is positively related to household economic status. Fertility aspirations may be positively or inversely related to household economic status; the more common pattern is an inverse relationship, namely, higher-status individuals desire fewer children.

- Differentials in fertility aspirations are less common and smaller in magnitude than differentials in the implementation of aspirations.

- The magnitude and even the direction of both of these differentials vary substantially across countries, especially differentials in fertility aspirations.

\section{AN EMPIRICAL INVESTIGATION USING DHS DATA}

\section{Methods}

We test the validity of these expectations through analysis of Demographic and Health Surveys (DHS) data. The information on household economic status collected in the DHS is limited, with measures of income and consumption expenditure usually unavailable. Those few DHS surveys that have measured household expenditures have employed a few brief items, falling well short of the more comprehensive approach that is standard in full-fledged household economic surveys. The lack of systematic measurement of income and consumption 
has long been considered a critical shortcoming of DHS surveys as a means of investigating linkages between economic status and demographic processes.

The DHS surveys do, however, collect information on the ownership of household assets, most of which are consumer durables but also include household amenities (electricity, source of drinking water, type of toilet facilities). From this information various indicators of household wealth can be constructed (e.g., via principal components analysis) (Filmer and Pritchett 2001; Rutstein and Johnson 2004). What such indicators represent has been a subject of debate. In an analysis of survey data from six countries, Montgomery et al. (2000) conclude that while asset holdings (including consumer durables) are only weakly predictive of per capita consumption per adult, they can be employed as valid proxies for long-run household standard of living when analyzing large samples, provided that other key confounding variables are controlled.

Accordingly, Montgomery and Hewett (2005) apply a factor analytic approach and find that poverty affects three facets of health, including unmet need for contraception, in urban areas of developing countries. Rutstein and Johnson (2004) find a weak association between asset holdings and per capita household expenditure in survey data from Guatemala. Nevertheless, they conclude that survey data on household assets provide a more valid picture of household economic status than do survey data on expenditures. Filmer and Pritchett (2001) are more optimistic about household wealth indicators: they argue that asset holdings are good proxies for long-run household wealth and are reasonably correlated with long-run consumption. Bollen et al. (2002), in an analysis of survey data from two countries, conclude that summations of household assets, using various weighting schemes, show stronger associations with fertility than do direct measures of household expenditures. Other published research demonstrates that household wealth indicators are significantly associated in the expected direction with children's schooling (Filmer and Pritchett 2001), type of attendant at birth (Rutstein and Johnson 2004; Montgomery and Hewett 2005), height-for-age (Montgomery and Hewett 2005), and contraceptive use (Rutstein and Johnson 2004).

In arguing for asset-based indicators, these authors revisit a fundamental debate about the relative merits of income versus consumption/expenditure (Deaton and Grosh 2000). This debate was resolved in favor of expenditure, partly on the grounds of practicality in the fieldfar fewer questionnaire items are required, and these items are thought to yield more valid information than inquiry on income-but also for more fundamental reasons. A substantial literature documents that household consumption (expenditure) varies much less over time than income (Townsend 1994; Amin, Rai, and Topa, 2003). Households have various means of protecting themselves from swings in income that could threaten consumption. These include formal and informal mechanisms of social protection, insurance, and credit (Townsend 1994; Alderman and Paxson 1992). Thus cross-sectional household asset indicators can be viewed as proxies for permanent income; they capture variation that is due in part to mechanisms households deliberately employ to shield themselves from short-term consumption threats. Asset-based indicators of poverty reflect in part successful household-level strategies to cope with risk.

The "household wealth index" is now an established variable in DHS surveys (Rutstein and Johnson 2004). Applying principal components analysis to the list of measured household durable assets $^{3}$ (each one represented by a 1/0 variable indicating presence/absence), a factor 
score can be obtained for each household. With this score households can be ranked from lowest to highest in terms of measured household durable assets. A household's ranking on this "wealth index" reflects its relative wealth as compared to other households in the same country at the same time historically. Therefore households that score low on this index are poor in relative terms; how poor they are in absolute terms cannot be ascertained from the index alone. Because absolute household wealth is obscured, cross-country differences in average wealth and cross-time changes in average wealth cannot be detected by the DHS wealth index (see discussion in Montgomery and Hewett 2005).

In the DHS main reports, the household wealth index is commonly included among the short list of background variables (along with place of residence, educational attainment, and so forth). It has been used in some multi-country tabulations of differentials in demographic and health outcomes (e.g., Gwatkin et al. 2004; Panel on Transitions to Adulthood in Developing Countries 2005; and for urban areas Panel on Urban Population Dynamics 2003). Among reproductive variables, the outcomes that have been examined include the total fertility rate (TFR), the adolescent fertility rate, use of modern contraception, and unmet need for contraception. Left unexamined are differentials in fertility aspirations: hence, existing tabulations do not permit consideration of the distinction between fertility aspirations and behavioral implementation of those aspirations - an essential distinction for both theoretical and policy purposes. Furthermore, heretofore the multi-country tabulations of differentials in reproductive variables according to household wealth have not been adjusted for other associated socioeconomic variables, such as place of residence (urban vs. rural) and the educational attainment of the respondent and/or her husband. (Montgomery and Hewett 2005 is an exception, but their analysis is confined to urban areas.) Without doubt, household wealth is associated with these other socioeconomic variables, which themselves are known to have substantial effects on reproductive attitudes and behaviors.

We analyze the most recent DHS survey conducted in the period 1990-2003 in 47 countries. ${ }^{4}$ More than half of these countries (27) are in sub-Saharan Africa, reflecting the more active program of DHS surveys in this region. For our analysis, the household wealth index is broken into three categories according to percentile ranking. We regard the lowest 40 percent as poor, the next 40 percent as middle, and the highest 20 percent as more affluent.

Some analysts have constructed the wealth index separately for urban and rural segments of the sample, recognizing that the distribution of assets differs radically between urban and rural populations (e.g., Panel on Urban Population Dynamics 2003). However, unless the ownership of such assets can be shown to have fundamentally different significance in urban and rural areas, separate construction of the wealth index for urban and rural subsamples is not required and, in fact, complicates the interpretation of results. Further, our analysis controls for urban/rural residence (via a dummy variable in the regression equation). Our urban/rural indicator includes both the actual effect of living in an urban or rural area and any effect of the construction of the index; therefore it acts as a control for systematic differences between urban and rural asset holdings as well as for urban/rural residence. We do not interpret the urban/rural coefficient causally, rather we include it only in its capacity as a control.

Two reproductive variables are examined, the first an indicator of fertility aspirations and the second an indicator of the implementation of fertility aspirations. Both are dichotomous 
variables: want no more children, and use of contraception for limiting purposes. For consistency in the sample across countries and dependent variables, the analysis of both variables is limited to women in a marital union at the time of the survey. Other sample restrictions and more details about the variables are as follows:

1. Want no more children. The sample excludes women who believe they are incapable of having another child (i.e., infecund).

2. Contraceptive use among those who seek to limit. Use among women who seek to limit childbearing is based on the DHS standard unmet need variable. Unmet need is non-use of contraception despite wanting to avoid pregnancy (Westoff 2001). This variable is constructed using an algorithm developed by Westoff and placed in the DHS standard recode file. The sample consists of women who say they want no more children; infecund and menopausal women are excluded from the sample. Contraceptive use among those who seek to limit is expressed as the inverse of the standard unmet need variable.

The analysis of contraceptive use is restricted to women who want no more children, thereby focusing attention on the implementation of preferences.

Logistic regression is used to adjust for other associated socioeconomic variables. In addition to the household wealth index, all equations include: place of residence (urban/rural); region of residence (defined on a country-specific basis); woman's educational attainment (three categories, according to years of schooling completed: <4 years, 4-7 years, 8+ years); number of living children; and woman's age. All of the categorical explanatory variables, including household wealth, are represented in the equations by a vector of indicator ("dummy") variables. All results presented here are derived from equations consisting of additive effects only; interactions between household wealth and place of residence were tested but did not prove informative. (This result provides further support for our decision not to construct the wealth index separately for urban and rural areas.) This model begs the question of how the various socioeconomic variables, including household wealth, are jointly determined (Bollen et al. 2001). We employ this simple model for heuristic purposes, as a means of estimating differentials according to household wealth that are adjusted for confounding variables. (The question of the causal structure that underlies relationships among this cluster of socioeconomic variables is addressed later in this paper, when we assess the relative strength of the effects of household wealth and women's educational attainment.)

Finally, to make the results more interpretable, we convert the regression estimates into predicted probabilities of wanting no more children and of contraceptive use among limiters. These are calculated for each of the three categories of household wealth, with other variables taking their actual values. Because these probabilities are derived from the regression estimates, they portray differentials according to household wealth that are adjusted for the other explanatory variables.

\section{Results}

Differentials by household wealth between the lowest 40 percent and either of the other two categories that are statistically significant at the .01 level are indicated in Table 1 , and the 
differentials themselves are displayed in Figures 1 and 2. An important finding in Table 1 is that statistically significant differentials are more common for contraceptive use among limiters (20 countries) than for fertility aspirations (13 countries). This is the case despite the markedly smaller samples for the analysis of contraceptive use among limiters. This result confirms our expectation that household wealth is more strongly associated with the implementation of fertility aspirations than with fertility aspirations per se. The absence of differentials in fertility aspirations in all Latin American countries except Guatemala stands out; evidently household economic status, net of urban/rural residence and women's educational attainment, has little bearing on the demand for children in this region.

The patterns of differentials are displayed in Figures 1 and 2. The bars in the figures represent the magnitude of the differential, in percentage points, between the lowest and highest categories of household wealth and between the lowest and middle categories. In most cases the larger differential is between the highest and lowest categories (shown in gray), hence this is the longer of the two overlapping bars. In those few instances where the larger differential is between the middle and lowest categories of household wealth, the longer of the two bars in Figures 1 and 2 is white. The predicted percentage of households belonging to the lowest category of household wealth, which serves as the reference value for the bars, is shown in parentheses after the country name. We note again that these differentials are derived from logit regression analyses that control for place of residence, region, education, number of living children, and age.

We draw the following conclusions from the differentials shown in Figures 1 and 2. First, the differentials are almost always monotonically increasing or decreasing; that is, the larger differential is between the lowest and highest categories of household wealth. The few exceptions-Ethiopia and Zambia for fertility aspirations, and Mozambique for contraceptive use among limiters - are located in eastern and southern Africa but otherwise do not appear to have obvious features in common (socioeconomic, programmatic) that would explain their nonmonotonic differentials. Explaining their eccentric patterns would require in-depth countryspecific investigation.

Second, not only are significant differentials in fertility aspirations less common than differentials in contraceptive use among limiters (as discussed above), but on balance the differentials in fertility aspirations are also smaller in magnitude. This result is as we hypothesized. Only one of the 13 significant differentials in fertility aspirations shown in Figure 1 exceeds 15 percentage points (Guatemala), whereas this magnitude characterizes a substantial fraction of the differentials in contraceptive use among limiters. Differentials of 10 percentage points or greater are the norm for contraceptive use among limiters but characterize only four out of 13 countries with significant differentials in fertility aspirations. Many countries could be selected to illustrate this point, for example:

Percentage point differential (highest vs. lowest wealth category) in:

$\underline{\text { Fertility Aspirations } \text { Contraceptive Use Among Limiters }}$

Guatemala

India

Zambia 
Regional patterns in the magnitude of the differentials resist concise summary. Even so, it seems fair to conclude that the differentials are larger in sub-Saharan Africa-eastern and southern Africa in particular. This is a noteworthy finding, because the African countries in general are poorer, with larger fractions of their populations in poverty (World Bank 2006a), and these countries have less capacity to soften the repercussions of household poverty through public and private provision of social and health services.

As for country characteristics other than regional location that are associated with the magnitude of the wealth differentials shown in Figures 1 and 2, none has emerged in our tentative exploration. Factors that might be worthy of consideration in a more thorough investigation include the nature of the economy (which in turn determines sources and potential uses of wealth) and the structure of family planning services (in particular, their effectiveness in reaching lower strata of the population).

As already stressed, in the analysis presented in Figures 1 and 2 absolute levels of household wealth are removed from view, hence only relative wealth is visible. But countries are known to differ substantially in level of absolute wealth, including the fraction of the population that is in poverty as conventionally determined. Table 1 and Figures 1 and 2 strictly speaking provide an analysis of the association of reproductive indicators with household wealth inequality, not an analysis of the association of fertility with household wealth per se. Only indirectly does this analysis shed light on effects of interrelations between fertility and poverty.

To focus on absolute levels of household wealth, we re-categorized the household wealth index on the basis of national prevalence of poverty (World Bank 2006b). Using the percentage of the population falling below the poverty line, we calculated two percentiles that serve as cut-points for reclassifying the DHS households into three groups: a percentile that is 10 points below the percentage in poverty, and a percentile that is 10 points above the percentage in poverty. We assumed that this revised categorization more effectively distinguishes poor from non-poor households. With this revised categorization of the household wealth index, we repeated the analysis of Figures 1 and 2 . The results are not shown here. ${ }^{5}$ For the most part, the pattern of differentials is the same under either categorization of the household wealth index, hence the conclusions from Figures 1 and 2 stand.

In considering the association of fertility with household wealth, one may ask how this association compares with the association of fertility with other basic socioeconomic variables. Perhaps no variable is as well-established as a correlate of reproductive attitudes and behaviors as educational attainment (Cochrane 1979; Jain 1981; Bongaarts 2003). Educational attainment is one of the control variables in the regressions from which Figures 1 and 2 are derived, hence these regressions also provide a basis for assessing the comparative explanatory strength of household wealth versus education.

This comparison, however, assumes that the effects of household wealth and education on fertility are additive, with correlation between the two variables due to other exogenous variables that are shared or distinctive to each variable. Most importantly, no causal paths between household wealth and education are assumed. This is a naïve model, because undoubtedly in most settings powerful causal mechanisms link household wealth and education, if not intragenerationally then certainly intergenerationally (Cochrane 1979; Dumas 
and Lambert 2005). Montgomery and Hewett (2005), for example, treat adult schooling as a determinant of both household wealth and reproductive and health outcomes.

Figure 3 sketches our understanding of how these two variables are linked. Two generations are represented in Figure 3, with fertility shown only for the second generation. In both generations, adult levels of educational attainment are a determinant of household wealth (causal paths $d_{1}$ and $d_{2}$ ), consistent with Montgomery and Hewett's (2005) model. We also posit cross-generational effects of educational attainment on wealth (causal path $\mathrm{q}_{1,2}$ ) and of wealth on educational attainment (causal path $\mathrm{p}_{1,2}$ ). The effects estimated in the regressions underlying Figures 1 and 2 are $b_{2}$ and $c_{2}{ }^{6}$

From Figure 3 it is clear that $b_{2}$ - the estimated effect of household wealth on fertility in our regressions - in part expresses effects of educational attainment in Generation 2 and educational attainment in Generation 1 , indicated by causal paths $\mathrm{d}_{2}$ and $\mathrm{q}_{1,2}$, respectively. Similarly, $c_{2}$ - the estimated effect of educational attainment on fertility - in part expresses effects of household wealth in Generation 1 , indicated by causal paths $\mathrm{p}_{1,2}$. Hence a full assessment of the repercussions for fertility of changes in the distributions of household wealth or of changes in educational attainment must take causal paths other than $b_{2}$ and $c_{2}$ (which we estimate) into consideration. Suppose, for example, that educational attainment is a critical mechanism for the perpetuation of household wealth within families across generations; causal paths $\mathrm{p}_{1,2}$ and $\mathrm{d}_{2}$ together represent this mechanism. If this is the case-and there is good reason to believe this is a fundamental causal process in contemporary economies-then the comparison of $b_{2}$ and $c_{2}$ would give a downwardly biased impression of the importance of household wealth relative to education. Equally, to the extent that household wealth is a function of education-causal path $\mathrm{q}_{1,2}$ and causal paths $\mathrm{n}_{1,2}$ and $\mathrm{d}_{2}$ together-then the comparison of $b_{2}$ and $c_{2}$ provides a downwardly biased impression of the importance of education in relation to household wealth.

Without empirical data on multiple generations at multiple points in time, it is not possible to estimate the full set of causal effects in Figure 3, hence we do not know whether our assessment of the relative importance of household wealth vs. schooling is markedly biased in one direction or another. For policy purposes, one wishes to know the long-term repercussions for fertility of changes in distributions of wealth and education, assuming these could be subject to modification through policies and programs. These repercussions occur through a process such as the one portrayed in Figure 3. With this qualification in mind, for now we simply compare $b_{2}$ and $c_{2}$, as represented by the coefficients (and associated predicted probabilities) from our logistic regressions.

There is another, minor methodological concern if we seek a level playing field for comparing the effects of household wealth and schooling, namely sample distributions across categories of these two variables. For this analysis, education is measured in years of schooling and grouped into three categories: $<4,4-7,8+$. To compare the effects of wealth and education, in each country we re-group the household wealth index into three categories that contain the same proportion of women as the three categories of education. The regressions of Figures 1 and 2 are then re-estimated employing this revised categorization of household wealth.

The results are shown in Figures 4 and 5. These are scatterplots comparing the magnitude of the effect of household wealth on fertility with the magnitude of the effect of educational attainment. Each effect is represented by the difference in predicted probability 
between the highest and lowest category (of household wealth and of educational attainment). The 45-degree line represents effects that are equal in magnitude; in countries falling below this line, the effect of education exceeds the effect of household wealth, whereas in countries falling above this line the opposite obtains. Our interpretation of these scatterplots takes into account both the number of countries falling above or below the diagonal line and the distance of countries from the diagonal line (the latter indicative of the amount by which one effect exceeds the other).

On the whole, effects of education exceed effects of household wealth, as indicated by the larger number of countries below the diagonal in both figures. As judged by a count of countries above or below the line, the dominance of education effects is slightly greater for fertility aspirations (Figure 4) than for contraceptive use (Figure 5). But if distance from the diagonal line is the criterion, if anything the education effects seem slightly more dominant for contraceptive use, a result consistent with our expectation that household wealth is more closely associated with the implementation of fertility aspirations (via contraceptive use) than with fertility aspirations per se. From the wealth and educational attainment regressions, we draw two conclusions. First, household wealth has effects over and above effects attributed to education. This conclusion emerges from multiple regression analysis and could not be ascertained from existing published tabulations. Second, as illustrated in Figures 4 and 5, more often than not the net effects of educational attainment are larger in magnitude than the net effects of household wealth. On these grounds alone one would favor schooling as a policy priority. We note again that this conclusion derives from analysis that does not take into account the various indirect and intergenerational causal links portrayed in Figure 3.

\section{Beyond The Wealth IndeX: The Poverty-Fertility NeXuS}

Analysis of DHS data documents the prevalence and magnitude of reproductive differentials according to a fundamental element of household economic status, namely household assets. Cross-national variability in these differentials can be assessed because the measurement of both household assets and fertility is standardized in the DHS. This remains, however, a cross-sectional analysis of differentials according to household wealth. We argue that our approach should be regarded as only a starting point for research on the relationship between economic factors and fertility - in particular, research on interrelations between poverty and fertility. In our view much of the recent empirical work on this topic relies on conceptualizations - sometimes explicit, more often implicit - that are simplistic and do not draw effectively on the recent theoretical and empirical literature in development economics.

While not always articulated in the recent literature, we sense that demographers view poverty simply as a lack of material resources at the household level. This conceptualization may serve the field adequately for the purpose of research on health and mortality: it is likely that the presence or absence of material resources accounts for a substantial portion of the observed differentials in health and mortality according to economic indicators, although one suspects the story is more complex (see Panel on Urban Population Dynamics 2003). But when we consider fertility, viewing poverty as a lack of material resources is insufficient, for two fundamental reasons. First, achieved fertility in most contemporary settings is largely a matter of individual choice (albeit socially constrained), with choice in turn primarily determined by 
goals consciously held and actively pursued by couples. And, as we argued above, for many reasons there may not be a simple monotonic relationship between fertility goals and the level of household material resources. Second, households' economic prospects are heavily influenced by their access to various types of markets and social resources. To the extent that fertility decisions are guided by forward-looking strategizing about economic prospects, current household economic resources may carry less weight than evaluations of future prospects (both opportunities and risks).

Sen's capabilities approach discusses reasons why the same income may not allow all households to function at the same level of well-being. Capability differences arising out of health are his classic example: poor health and associated disability will lead to very different levels of well-being even at the same level of income, depending on the level of appropriate forms of public support. Education and social status may function in similar ways. Education can enable individuals to capitalize more of a given level of income. The same applies to social and political connections. Even though income is a critical element of well-being, these other variables can play a crucial role in converting income for distinct "functioning" (Sen 1999). Fertility aspirations and the implementation of those aspirations are the aspects of functioning that are of interest in this paper.

Another major theme in the recent economics literature is that poverty is a function of absent or deficient access to markets. The poor typically have less access to formal markets for capital, insurance, credit, and labor, and may thus have to resort to non-market institutions to address economic stress. These informal mechanisms draw heavily on social capital; hence in seeking to preserve and advance their households' economic fortunes, the poor may be relatively more reliant than the wealthy on factors such as social connectedness and community trust. Indeed, their relative lack of access to formal markets compels the poor to rely more on social institutions for income generation in the first place. While demographers have recognized the role of social networks and social capital in forming and implementing fertility aspirations, the association of social capital with poverty is not explicitly discussed.

Townsend's (1994) study of villages in semi-arid areas of India found evidence of considerable risk insurance across households. Cain (1981) compared semi-arid, drought-prone Indian villages to a flood-prone and similarly high-risk village in Bangladesh, and argued that the risk environment was much more precarious in Bangladesh because of the absence of credit markets. Households in rural Bangladesh frequently resorted to distress sale of land, a response that sent them further down the spiral of poverty. In the Indian villages credit was more readily available to help poor households tide over income shortfalls. This comparison led Cain to posit that the absence of credit markets (and insurance mechanisms more generally) resulted in higher fertility in Bangladesh relative to villages in India.

Cain also described a class of risks specific to women, derived from the patriarchal gender system that, among other things, leads to women's exclusion from labor markets. Because of these exclusions, women are strongly motivated to have children so that at a later stage in life, when they may find themselves widowed, they will have mature sons without whom they would lose most forms of entitlement in their marital home. A household's ability to cope with vulnerability to a sudden shortfall in income can be consequential in terms of how they perceive economic risk. Moreover, these household capabilities in all likelihood differ 
across households within societies as well as across societies. These aspects of social structure result in the production of social capital for individuals and households.

\section{Social capital}

With some exceptions, as discussed above, much of the research on poverty and fertility implicitly treats households as autonomous units that must fend for themselves, with perhaps some recourse to public and private social and health services (micro-credit, schools, reproductive health services, and so forth). We include in this characterization most research that uses the DHS household wealth index. This is a behavioral model that neglects numerous social connections. Bourdieu cogently characterized the implicit model in this body of work and suggested how a more expansive notion of "capital" would vastly improve this model:

The social world is accumulated history, and if it is not to be reduced to a discontinuous series of instantaneous mechanical equilibria between agents who are treated as interchangeable particles, one must reintroduce into it the notion of capital and with it accumulation and all its effects. Capital is .... what makes the games of society - not least, the economic game — something other than simple games of chance offering at every moment the possibility of a miracle. Roulette, which holds out the opportunity of winning a lot of money in a short space of time, and therefore of changing one's social status quasi-instantaneously, and in which the winning of the previous spin of the wheel can be staked and lost at every new spin, gives a fairly accurate image of this imaginary universe of perfect competition or perfect equality of opportunity, a world without inertia, without accumulation, without heredity or acquired properties, in which every moment is perfectly independent of the previous one, every soldier has a marshal's baton in his knapsack, and every prize can be attained, instantaneously, by everyone, so that at each moment anyone can become anything. Capital, which, in its objectified or embodied forms, takes time to accumulate and which, as a potential capacity to produce profits and to reproduce itself in identical or expanded form, contains a tendency to persist in its being, is a force inscribed in the objectivity of things so that everything is not equally possible or impossible. (Bourdieu 1986)

This is Bourdieu's introduction to the case for what he terms "cultural capital" and "social capital," the latter defined as "the aggregate of the actual or potential resources which are linked to possession of a durable network of more or less institutionalized relationships of mutual acquaintance and recognition." Bourdieu argues that a person's social capital is determined by the size of his or her relationship network, the sum of its cumulated resources (both cultural and economic), and how successfully (quickly) he or she can leverage them. In its key features, this notion of social capital is essentially the same as Coleman's $(1988,1990)$, which has become a central organizing concept in research on poverty in the United States and in developing countries (e.g., Narayan and Pritchett 1999).

Bourdieu sets the stage for a consideration of social capital in a manner that is particularly helpful for our discussion: by subsuming all types of capital under a more general concept, he reveals the imbalance in examining just one type and neglecting the others. The 
DHS household wealth index captures the accumulation of economic capital. We believe that social capital (in its variants) will further advance our understanding of the observed associations between household assets (economic capital) and reproductive attitudes and behaviors.

To elaborate our position, we make social capital more specific and concrete through the concepts of social learning and social networks. "Social learning" refers to informational gains through social interaction; that is, knowledge is a resource acquired socially. Knowledge is defined broadly to include everything from technical knowledge to behavioral norms. A critical form of social learning is observing the experiences of other persons: what choices others have made when faced with certain predicaments, and the consequences of those choices. This form of social learning does not require a mutually recognized interpersonal relationship, indeed it can occur at a distance. Social learning is a complex behavioral and cognitive process that encompasses both the social aspects of information acquisition and the filtering or distillation of that information into terms that are meaningful to individual choice (Carley 2001).

Social learning is a pervasive feature of social experience but is especially salient in circumstances of risk and uncertainty, and this is what makes the concept of particular value when attempting to understand the nexus of poverty and fertility. Social learning can inform both economic aspirations (Ray 2006) and childbearing aspirations (Casterline 2001). Further, social learning will inform individuals' perceptions of their environments of risk and their consequent vulnerability (economic and otherwise); hence, individuals with apparently identical household economic circumstances - as represented by the assets they possess - may assess their future risks quite differently (differential assessments that may, in fact, be correct). Similarly, through social learning individuals can learn about alternative means for regulating fertility and the costs and benefits of those alternatives (Montgomery and Casterline 1996). Finally, social learning informs individuals' awareness of resources for coping with distress, both economic and reproductive. The important point here is that if individuals learn fromborrow from - the attitudes and experiences of others, this undermines any strict mechanical relationship between their own household economic situation and other choices they make, including reproductive choices.

"Social network" refers to concrete interpersonal connections among persons. These connections can be the conduit for the transfer of various resources, including knowledge: hence "social learning" and "social networks" are inseparable concepts. In this discussion, the concept of social network subsumes local community organizations. Such organizationsformal and informal, voluntary and involuntary - have received widespread attention in recent years in the poverty and development literature. "Social network" also subsumes those social connections based on kinship. In terms of the association between household economics and fertility, social networks can serve two types of functions - ex ante and ex post, respectivelyas discussed in earlier: first, they can provide protection against distress via various incomesharing and consumption-smoothing mechanisms; second, they can provide resources for coping with distress, economic and reproductive, once it occurs. Concerning reproductive distress, we note that in some societies the adoption or fostering-out of children is a means for coping with childbearing shortfalls and excesses. 


\section{Social capital and fertility}

Having defined and briefly reviewed two facets of social capital (social learning and social networks), we ask how these might bear on the association between household economic circumstances and fertility. It seems likely that, on balance, social learning and social networks attenuate the relationships that might otherwise be observed. In its various forms, social capital tends to offset and counteract the effects of household-level economic capital on reproductive strategizing and on reproductive outcomes: economic and fertility aspirations will align less perfectly with household economic circumstances; individuals' perceptions of risk (and the attendant sense of vulnerability) will not be driven solely by household circumstances, but instead will be informed by assessments of group-level risk; and coping tactics will exploit extra-household resources.

Hence, we should not expect to observe the stark effects of household wealth on reproduction that would hold in a hypothetical society in which households acted in isolation from one another. We must, however, qualify this generalization by making it contextually specific. The character of social capital varies from society to society and among various subgroups in any given society. It might well amplify differentials according to household economic status in some settings. Consider the role of social capital in the formation of aspirations (economic and reproductive), and suppose that upward-mobility aspirations and small-family aspirations are strongly correlated. In some settings social learning might result in greater confidence about prospects for upward mobility among the non-poor and excessive pessimism about economic prospects among the poor; everything else being equal, this would amplify the association between economic circumstances and fertility. Or consider the role of social capital in determining the availability of social services. For this purpose, in some settings social networks among the non-poor may be more efficient in linking individuals to reproductive health services than comparable networks among the poor. Or consider the role of social capital in coping with distress. In some settings the net gain in coping resources acquired socially by the non-poor may be much more consequential than those acquired socially by the poor.

Economic and social capital will often be positively associated-those who possess more of one also possess more of the other. In itself, this positive association should result in the two forms of capital reinforcing each other. But at issue is not the simple association between the two forms of capital, but rather the proportionate effect of the available social capital on household-level strategizing about economics and about reproduction. Equivalent amounts of social capital might have varying effects on the decisions of the poor and non-poor. To illustrate, suppose that beliefs about the association between family size and children's later socioeconomic prospects are acquired through social learning. Suppose, further, that the poor average about five children and the wealthy average about three. For the poor, a vague belief acquired through social learning that children from smaller families have better chances of socioeconomic success in later life might lead to a decline in the average number of children desired from five to three (a 40 percent reduction), that is, down to a moderate size that still allows most couples to have children of both sexes. Equivalent beliefs acquired through social learning might have no impact on the wealthy; rather, they might require relatively firm evidence of improved socioeconomic prospects for their children before they would aspire to 
stop at two children on average (a 33 percent reduction). Hence, the same amount of social learning might have different proportionate impacts on fertility aspirations of the poor and the wealthy. This simple hypothetical example makes the more general point that the poor and nonpoor can differ both in their access to social capital and in the (per unit) effect of social capital on their strategizing about fertility.

\section{CONCLUSION}

Our aim in this paper has been to highlight important omissions in existing work and, in particular, to suggest promising directions for extending and enriching research on the nexus of poverty and fertility. The empirical analysis uses an income measure of poverty, namely household asset holding, to show that the association between poverty and fertility is by no means uniform across countries. By distinguishing between fertility aspirations and the implementation of those aspirations, we document that poverty is associated less with fertility aspirations than with the ability to implement those aspirations.

The recent literature on poverty in low-income countries places increasing emphasis on the role of social capital in determining the risk of impoverishment and the means for coping with it. Poverty defined simply as a lack of resources is seldom the exclusive focus in this literature. Social capital has, of course, figured centrally in fertility theory as well during the past decade or two. Thus, social capital, variously defined, is a key point of convergence between theories of poverty and fertility. The specific aspect of social capital that is stressed in recent research on both poverty and fertility is the social cohesion of the household's immediate environment. This cohesion is most directly characterized in terms of social networks of knowledge-sharing (with knowledge broadly defined to include, for example, perceptions of vulnerability to economic shocks and notions about the costs and benefits of children), income support, and the provision of ex post support during times of economic distress. The last can be regarded as an informal insurance mechanism.

By no means do we dismiss the role of household-level resources in determining fertility aspirations and outcomes. Rather, we argue that resources per se have a more direct and dominant influence on fertility control behaviors (i.e., the implementation of fertility aspirations) as compared to their influence on fertility aspirations. Hence fertility behavior such as use of contraception is more directly related to household wealth than are fertility aspirations, as demonstrated in the empirical analysis of DHS data on contraceptive use among limiters.

Turning to aspirations and the "aspirations gap," we believe that the relationship between economic and childbearing aspirations - and, in particular, what this implies for the association between economic status and fertility-needs to be reconceptualized. Here our argument is heavily influenced by a recent piece by the development economist Debraj Ray (2006) in which he argues that poverty is both a cause and an effect of an "aspirations failure." Aspirations are, of course, a central element in most fertility models, but the likely effect of household economic status - and poverty in particular - has been under-developed. Ray argues the need to consider both the macro-level and individual-level effects of poverty and aspirations. Further exploration of these ideas and their specific application to decisions about fertility can yield important results. 
Finally, these arguments need to be validated empirically. Our review suggests that to advance understanding of the nexus of poverty and fertility, certain data investments would be constructive. First, the list of economic variables needs to be expanded:

1. In addition to static descriptions of current status, some effort should be made to capture poverty dynamics by recording the recent history of changes in economic status. For this purpose poverty surveys make use of several types of indicators, for example questions on periods of shortage during the past year and questions on changes in asset holding.

2. An effort to capture economic vulnerability would help to distinguish income uncertainty versus consumption risk.

3. Measurement of perceptions of risk and risk aversion would be of special relevance for research on the poverty-fertility association.

4. A concise effort to measure economic aspirations would include optimism/pessimism about the achievability of these aspirations, and, from a more negative perspective, the extent of anxiety and distress about future economic prospects.

It should be clear from the above that we also place some premium on the measurement of social capital. To this end, there are now some relatively well-established measurement devices:

5. Social networks - their composition and the resources exchanged.

6. Participation in local organizations, formal and informal.

7. Trust in local social capital and the concrete extent of reliance.

Turning to fertility data, we advocate more explicit inquiry about how fertility aspirations relate to other individual and household aspirations:

8. Exploration of reproductive goals and how they are perceived to bear on the achievement of other valued goals.

While we believe progress can be made on all of these fronts in structured survey inquiry, clearly some of these issues lend themselves to qualitative investigation as well. This is particularly the case for subjective factors related to risk, aspirations, and coping strategies. There is evidence, for example, that perceptions of risk can be at odds with reality, yet these perceptions may have a major determining role in anticipatory behaviors such as fertility. These are subtle matters of the human psyche, and no doubt much can be learned through skillful semi-structured and unstructured interviewing. Such interviews could carefully explore how individuals jointly strategize about childbearing in relation to other facets of individual and household well-being.

We believe that there has been very little qualitative investigation of this kind during the past decade or so. Strangely, rigorous qualitative research has been pushed to the margin of the field in societies that have experienced significant fertility decline, as if qualitative work could inform the field about high-fertility regimes but not about regimes in mid-decline or postdecline. Hence we are largely in the dark about how individuals in societies with intermediate 
levels of fertility - India, Indonesia, Bangladesh, Egypt—strategize about fertility in relation to other domains of their lives, including especially economic domains. A large portion of humanity resides in such societies. We can imagine reproductive-age adults in these societies weighing the advantages and disadvantages of having two versus three versus four children, with concerns about economic survival and success always looming nearby. This presents a potentially highly productive opportunity to enrich demography with substantive social science research.

\section{NOTES}

$1 \quad$ Montgomery and Ezeh (2005) provide a comprehensive framework for understanding the multiple dimensions of urban poverty in Africa that may be usefully extended in future research.

2 We prefer the term fertility aspirations to fertility desire, more commonly used by demographers, because we seek to address a larger audience of sociologists and economists for whom desires may have a greater component of whimsy than we mean to imply. Aspirations also connotes thought processes that are more concrete than desires.

3 Similar to the construction employed by Filmer and Pritchett (2001), goods included in the asset index can be divided into two types: consumer durables (radio, television, bicycle, motorcycle, car, refrigerator) and housing characteristics (water source, sanitation, number of rooms, building materials, availability of electricity). The questions on asset ownership are relatively consistent across surveys; only a limited number of surveys are missing any of these variables.

4 The former Soviet republics of Central Asia are excluded. Yemen is excluded from the analysis of contraceptive use among limiters, because requisite information was not collected, and in addition from the analysis of Figures 4 and 5, because its educational distribution is too skewed.

$5 \quad$ Results are available from samin@popcouncil.org

6 To simplify this discussion, Figure 3 does not show fertility in the first generation, and therefore neglects the possibility that first-generation fertility will have some determinative influence on socioeconomic status in the second generation. This possibility, however, provides an important motivation for considering the impact of economic status on fertility, inasmuch as fertility differentials may be one mechanism for the intergenerational reproduction of social class. See, e.g., Lam (1986) and Williamson (2001). 


\section{REFERENCES}

Ahlburg, Dennis. 1998. "Intergenerational transmission of poverty," American Economic Review 88(2): 265-270, Papers and Proceedings of the hundred and tenth annual meeting of the American Economic Association.

Alderman, Harold and Christine H. Paxson. 1992. "Do the poor insure? A synthesis of the literature on risk and consumption in developing countries," Policy Research Working Papers, Agricultural Policies, Agriculture and Rural Development Department, World Bank. WPS 1008.

Amin, Sajeda, Ashok Rai, and Giorgio Topa. 2003. "Does microcredit reach the poor and vulnerable? Evidence from northern Bangladesh," Journal of Development Economics 70(1): 59-82.

Becker, Gary S. 1991. A Treatise on the Family. Cambridge MA: Harvard University Press.

Becker, Gary S. and H.G. Lewis. 1973. "On the interaction between the quantity and quality of children,” Journal of Political Economy 81(2) Supplement: S279-S288.

Becker, Gary S., Kevin M. Murphy, and Robert Tamura. 1990. "Human capital, fertility, and economic growth,” Journal of Political Economy 98(5) Part 2: S12-S37.

Bengtsson, Tommy and Martin Dribe. 2006. "Deliberate control in a natural fertility population: Southern Sweden, 1766-1864," Demography 43(4): 727-746.

Bernstein, Stan (with Charlotte Juul Hansen). 2006. Public Choices, Private Decisions: Sexual and Reproductive Health and the Millennium Development Goals. New York: UN Millennium Project.

Bollen, Kenneth A., Jennifer L. Glanville, and Guy Stecklov. 2001. "Socioeconomic status and class in studies of fertility and health in developing countries," Annual Review of Sociology 27: 153-185.

- 2002. "Economic status proxies in studies of fertility in developing countries: Does the measure matter?," Population Studies 56(1): 81-96.

Bongaarts, John. 2003. "Completing the fertility transition in the developing world: The role of educational differences and fertility preferences," Population Studies 57(3): 321-335.

Bourdieu, Pierre. 1986. "The forms of capital," in J.G. Richardson (ed.), Handbook of Theory and Research for the Sociology of Education. New York: Greenwood Press, pp. 241258.

Cain, Mead. 1981. "Risk and insurance: Perspectives on fertility and agrarian change in India and Bangladesh," Population and Development Review 7(3): 435-474. 
Carley, Kathleen M. 2001. "Learning and using new ideas: A socio-cognitive perspective," in J. Casterline (ed.), Diffusion Processes and Fertility Transition. Washington, DC: National Academy Press, pp. 181-209.

Casterline, John. 2001. "Introduction," in J. Casterline (ed.), Diffusion Processes and Fertility Transition. Washington, DC: National Academy Press, pp. 1-38.

Cochrane, Susan Hill. 1979. Fertility and Education: What Do We Really Know? Washington, DC: World Bank.

Coleman, James S. 1988. "Social capital in the creation of human capital," American Journal of Sociology 94: S95-S120.

. 1990. Foundations of Social Theory. Cambridge, MA: Harvard University Press.

Deaton, Angus. 2006. "Measuring poverty," in A.V. Banerjee, R. Bénabou, and D. Mookherjee (eds.), Understanding Poverty. New York: Oxford University Press.

Deaton, Angus and Margaret Grosh. 2000. "Consumption," in M. Grosh and P. Glewwe (eds.), Designing Household Survey Questionnaires for Developing Countries: Lessons from Ten Years of the Living Standards Measurement Study. Washington, DC: World Bank, pp. 91-133.

Dumas, Christelle and Sylvie Lambert 2005. "Patterns of intergenerational transmission of education: The case of Senegal," Working Paper CEPREMAP 0520, Center for Economic Research and its Applications. Paris.

Easterlin, Richard A. 1975. "An economic framework for fertility analysis," Studies in Family Planning 6(3): 54-63.

Eastwood, Robert and Michael Lipton. 2001. "Demographic transition and poverty: Effects via economic growth, distribution, and conversion," in N. Birdsall, A.C. Kelley, and S.W. Sinding (eds.), Population Matters: Demographic Change, Economic Growth, and Poverty in the Developing World. New York: Oxford University Press, pp. 213-259.

Filmer, Deon and Lant H. Pritchett. 2001. "Estimating wealth effects without expenditure data - or tears: An application to educational enrollments in states of India," Demography 38(1): 115-132.

Galloway, Patrick R. 1988. "Basic patterns in annual variations in fertility, nuptiality, mortality, and prices in pre-industrial Europe," Population Studies 42(2): 275-303.

Grady, William R., Daniel H. Klepinger, and John O.G. Billy. 1993. "The influence of community characteristics on the practice of effective contraception," Family Planning Perspectives 25(1): 4-11. 
Greene, Margaret E. and Thomas Merrick. 2005. "Poverty reduction: Does reproductive health matter?," HNP Discussion Paper. Washington, DC: World Bank.

Gwatkin, Davidson R. et al. 2004. Socioeconomic Differences in Health, Nutrition, and Population. Second Edition. Washington, DC: World Bank.

Hermalin, Albert. 1983. "Fertility regulation and its costs: A critical essay," in R.A. Bulatao and R.D. Lee (eds.), Determinants of Fertility in Developing Countries, Volume II. New York: Academic Press, pp. 1-53.

Jahn, Albrecht, Marga Kowalewski, and Suleiman S. Kimatta. 1998. "Obstetric care in Southern Tanzania: Does it reach those in need?," Tropical Medicine and International Health 3(11): 926-932.

Jain, Anrudh. 1981. "The effect of female education on fertility: A simple explanation," Demography 18(4): 577-595.

Kabeer, Naila. 2001. "Ideas, economics and the 'sociology of supply': Explanations for fertility decline in Bangladesh,” Journal of Development Studies Vol. 38(1): 29-70.

Kelley, Allen C. and Robert M. Schmidt. 2001. "Economic and demographic change: A synthesis of models, findings, and perspectives." in N. Birdsall, A.C. Kelley, and S.W. Sinding (eds.), Population Matters: Demographic Change, Economic Growth, and Poverty in the Developing World. New York: Oxford University Press, pp. 67-105.

Kremer, Michael and Daniel Chen. 1999. "Income-distribution dynamics with endogenous fertility," American Economic Review 89(2): 155-160.

Lam, David. 1986. "The dynamics of population growth, differential fertility, and inequality," American Economic Review 76(5): 1103-1116.

Lee, James Z. and Wang Feng. 1999. One Quarter of Humanity: Malthusian Mythology and Chinese Realities, 1700-2000. Cambridge, MA: Harvard University Press.

Lloyd, Cynthia B. 1994. "Investing in the next generation: The implications of high fertility at the level of the family," in R. Cassen et al. (ed.), Population and Development: Old Debates, New Conclusions. Washington, DC: Overseas Development Council, pp. 181202.

Mason, Andrew (ed.). 2001. Population Change and Economic Development in East Asia: Challenges Met, Opportunities Seized. Stanford, CA: Stanford University Press.

Merrick, Thomas W. 2002. "Population and poverty: New views on an old controversy," International Family Planning Perspectives 28(1): 41-46. 
Montgomery, Mark R. and John B. Casterline. 1996. "Social learning, social influence, and new models of fertility," Population and Development Review 22 (Supp.): 151-175.

Montgomery, Mark R. and Alex C. Ezeh. 2005. "Urban health in developing countries: Insights from demographic theory and practice," in S. Galea and D. Vlahov (eds.), Handbook of Urban Health: Population, Methods and Practice. New York: Springer.

Montgomery, Mark R., Michele Gragnolati, Kathleen A. Burke, and Edmundo Paredes. 2000. "Measuring living standards with proxy variables," Demography 37(2): 155-174.

Montgomery, Mark R. and Paul C. Hewett. 2005. "Urban poverty and health in developing countries: Household and neighborhood effects," Demography 42(3): 397-425.

Narayan, Deepa and Lant Pritchett. 1999. "Cents and sociability: Household income and social capital in rural Tanzania," Economic Development and Cultural Change 47(4): 871898.

Panel on Transitions to Adulthood in Developing Countries, National Research Council. 2005. Growing Up Global: The Changing Transitions to Adulthood in Developing Countries. Washington, DC: National Academies Press.

Panel on Urban Population Dynamics, National Research Council. 2003. Cities Transformed: Demographic Change and Its Implications in the Developing World. Washington, DC: National Academies Press.

Pebley, Anne R., Noreen Goldman, and Germán Rodríguez. 1996. "Prenatal and delivery care and childhood immunization in Guatemala: Do family and community matter?," Demography 33(2): 231-247.

Ray, Debraj. 2006. "Aspirations, poverty, and economic change," in A.V. Banerjee, R. Bénabou, and D. Mookherjee (eds.), Understanding Poverty. New York: Oxford University Press, pp. 409-421.

Rutstein, Shea Oscar and Kiersten Johnson. 2004. DHS Comparative Reports No. 6: The DHS Wealth Index. Calverton, MD: ORC Macro.

Sanderson, Warren. 1976. "On two schools of the economics of fertility, " Population and Development Review 2(3/4):469-477.

Schultz, T. Paul. 2006. "Fertility and income," in A.V. Banerjee, R. Bénabou, and D. Mookherjee (eds.), Understanding Poverty. New York: Oxford University Press, pp. $125-141$.

Sen, Amartya Kumar 1983. "Poor, relatively speaking," Oxford Economic Papers, New Series, 35(2):153-169. 
- 1999. Development as Freedom. New York: Alfred A. Knopf.

Stephenson, Rob and Amy Ong Tsui. 2002. "Contextual influences on reproductive health service use in Uttar Pradesh, India," Studies in Family Planning 33(4): 309-320.

Townsend, Robert. 1994. "Risk and insurance in village India," Econometrica 62(3): 539-591.

Westoff, Charles F. 2001. "Unmet need at the end of the century," DHS Comparative Report Number 1. Calverton, MD: ORC Macro.

Williamson, Jeffrey G. 2001. "Demographic change, economic growth, and inequality," in N. Birdsall, A.C. Kelley, and S.W. Sinding (eds.), Population Matters: Demographic Change, Economic Growth, and Poverty in the Developing World. New York: Oxford University Press, pp. 106-136.

World Bank. 2006a. 2006 World Development Indicators. Washington, DC: World Bank.

—. 2006b. World Development Indicators. http://devdata.worldbank.org/data-query/ 
Table 1. Summary table showing statistically significant effects of poverty on fertility aspirations and contraceptive use

\begin{tabular}{|c|c|c|}
\hline Region and Country & $\begin{array}{c}\text { Want no more } \\
\text { children }\end{array}$ & $\begin{array}{c}\text { Contraceptive use } \\
\text { among limiters }\end{array}$ \\
\hline \multicolumn{3}{|c|}{ Sub-Saharan Africa } \\
\hline Benin & $\mathrm{X}$ & \\
\hline \multicolumn{3}{|l|}{ Burkina Faso } \\
\hline \multicolumn{3}{|l|}{ Cameroon } \\
\hline \multicolumn{3}{|c|}{ Central African Republic } \\
\hline \multicolumn{3}{|l|}{ Chad } \\
\hline \multicolumn{3}{|l|}{ Comoros } \\
\hline Cote d'Ivoire & & $\mathrm{X}$ \\
\hline Ethiopia & $\mathrm{X}$ & $\mathrm{X}$ \\
\hline \multicolumn{3}{|l|}{ Gabon } \\
\hline \multicolumn{3}{|l|}{ Ghana } \\
\hline \multicolumn{3}{|l|}{ Guinea } \\
\hline Kenya & & $\bar{X}$ \\
\hline Madagascar & $\mathrm{X}$ & $\mathrm{X}$ \\
\hline Malawi & & $\mathrm{X}$ \\
\hline \multicolumn{3}{|l|}{ Mali } \\
\hline Mozambique & & $\mathrm{X}$ \\
\hline Namibia & $\bar{X}$ & $\mathrm{X}$ \\
\hline \multicolumn{3}{|l|}{ Niger } \\
\hline \multicolumn{3}{|l|}{ Nigeria } \\
\hline Rwanda & & $\bar{X}$ \\
\hline \multicolumn{3}{|l|}{ Senegal } \\
\hline South Africa & $\bar{X}$ & $\bar{X}$ \\
\hline \multicolumn{3}{|l|}{ Tanzania } \\
\hline Togo & $\mathrm{X}$ & \\
\hline Uganda & & $\mathrm{X}$ \\
\hline Zambia & $\mathrm{X}$ & $\mathrm{X}$ \\
\hline Zimbabwe & & \\
\hline \multicolumn{3}{|c|}{ North Africa and West Asia } \\
\hline \multicolumn{3}{|l|}{ Egypt } \\
\hline Jordan & $\mathrm{X}$ & $\mathrm{X}$ \\
\hline Morocco & & $\mathrm{X}$ \\
\hline \multicolumn{3}{|l|}{ Turkey } \\
\hline Yemen & $\mathrm{X}$ & $\mathrm{N} / \mathrm{A}$ \\
\hline \multicolumn{3}{|c|}{ South and Southeast Asia } \\
\hline \multicolumn{3}{|c|}{ Bangladesh } \\
\hline India & $\mathrm{X}$ & $\mathrm{X}$ \\
\hline Indonesia & & $\mathrm{X}$ \\
\hline Nepal & $\mathrm{X}$ & $\mathrm{X}$ \\
\hline Pakistan & $\mathrm{X}$ & $\mathrm{X}$ \\
\hline Philippines & & \\
\hline Vietnam & & \\
\hline Latin America an & & \\
\hline Bolivia & & \\
\hline Brazil & & $\bar{X}$ \\
\hline Colombia & & \\
\hline Dominican Repuk & & \\
\hline Guatemala & $\bar{X}$ & $\mathrm{X}$ \\
\hline Haiti & & \\
\hline Nicaragua & & $\mathrm{X}$ \\
\hline Peru & & \\
\hline Central Asia & & \\
\hline Armenia & & \\
\hline Kazakhstan & & \\
\hline Kyrgyz Republic & & \\
\hline Uzbekistan & & \\
\hline
\end{tabular}


Figure 1. Percentage point difference in percent of currently married women not wanting another child: Contrast with lowest 40 percent on wealth index

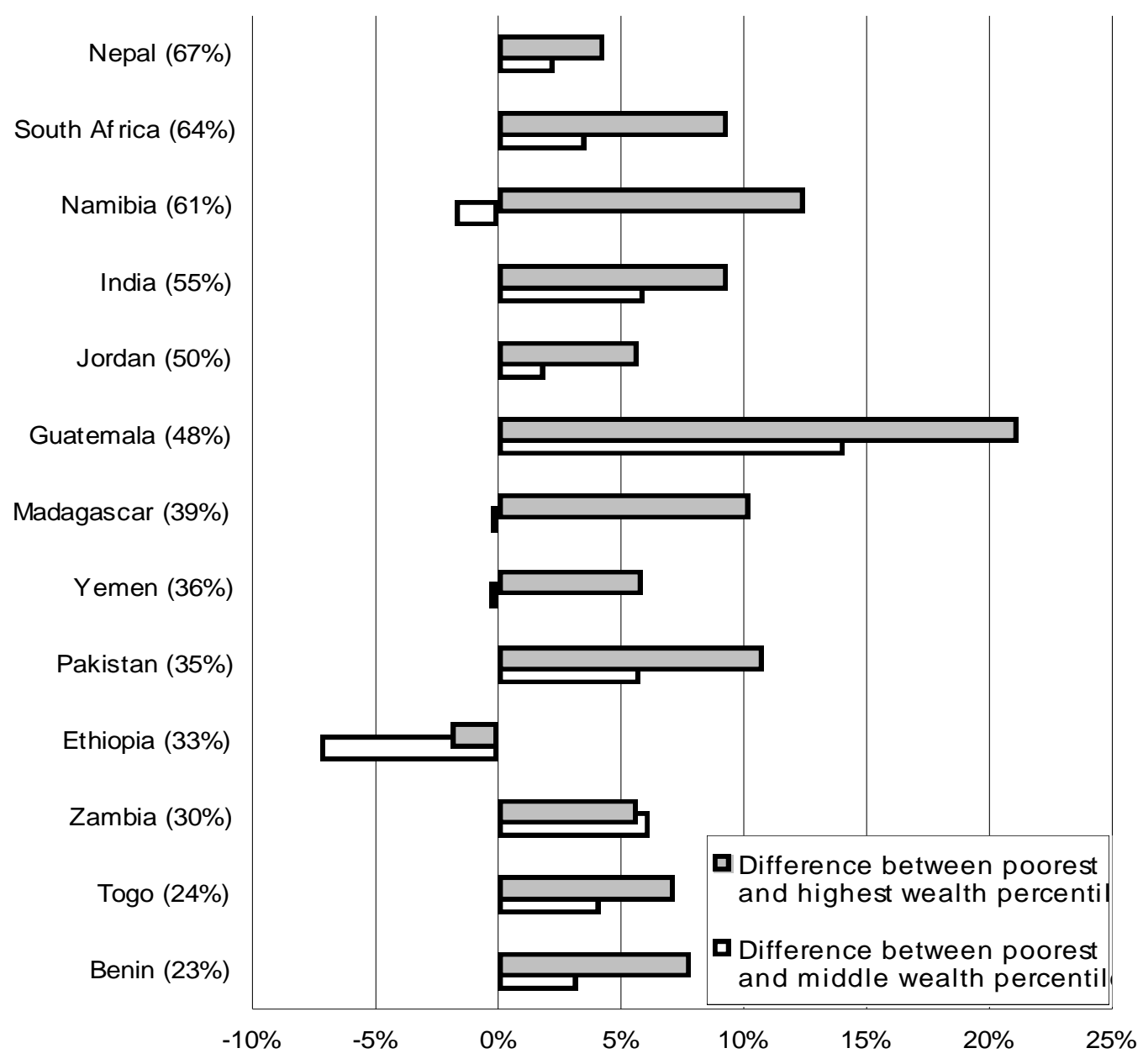

Notes: Adjusted differentials from logit regression analysis, differentials significant at .01 level. Countries are listed in descending order according to predicted percentage of households belonging to lowest wealth category, shown in parentheses. 
Figure 2a. Percentage point difference in contraceptive use among currently married women in sub-Saharan Africa who seek to limit childbearing: Contrast with lowest 40 percent on wealth index

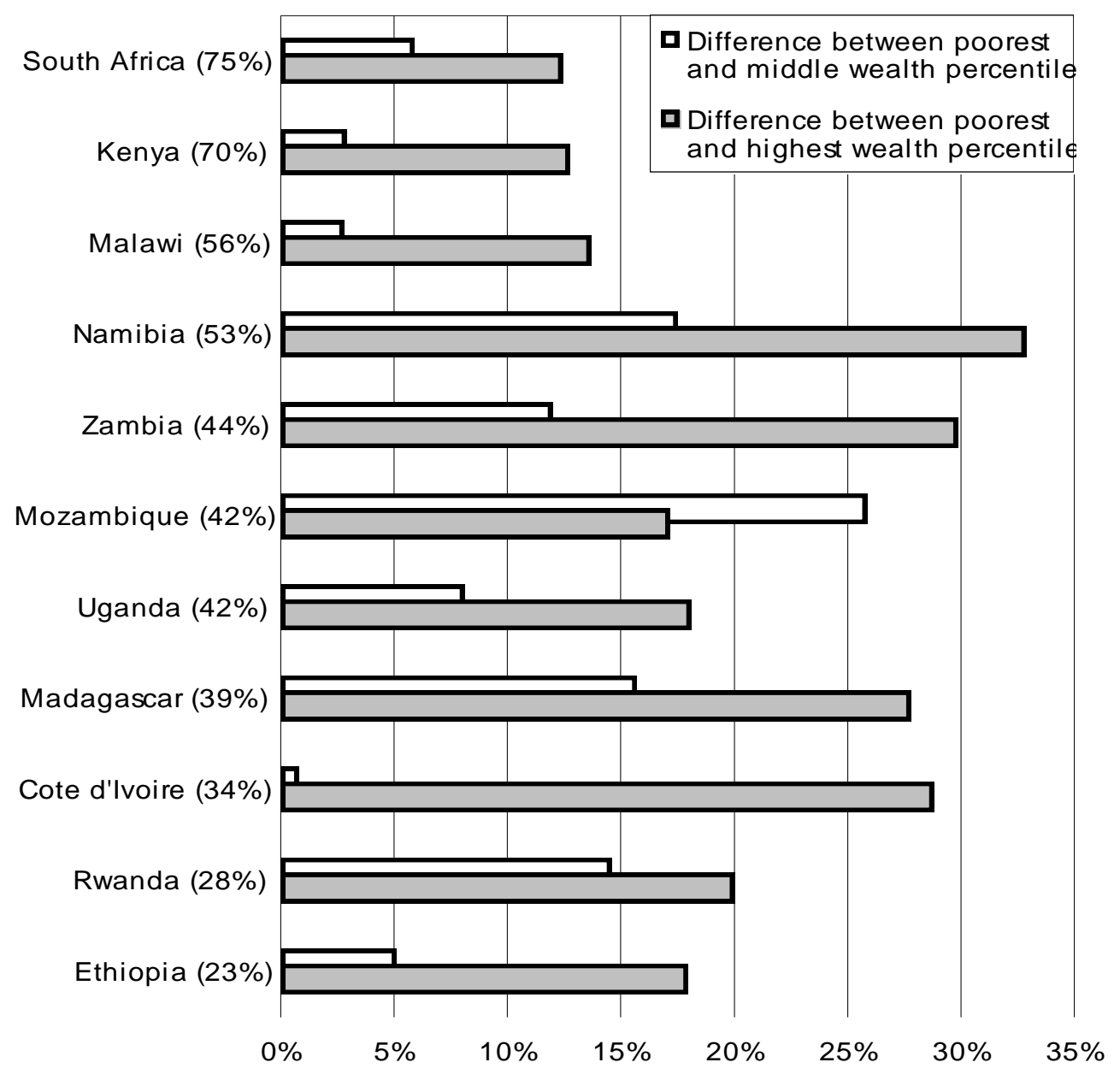

Notes: Adjusted differentials from logit regression analysis, differentials significant at .01 level. Countries are listed in descending order according to predicted percentage of households belonging to lowest wealth category, shown in parentheses. 
Figure 2b. Percentage point difference in contraceptive use among currently married women in other regions who seek to limit childbearing: Contrast with lowest 40 percent on wealth index

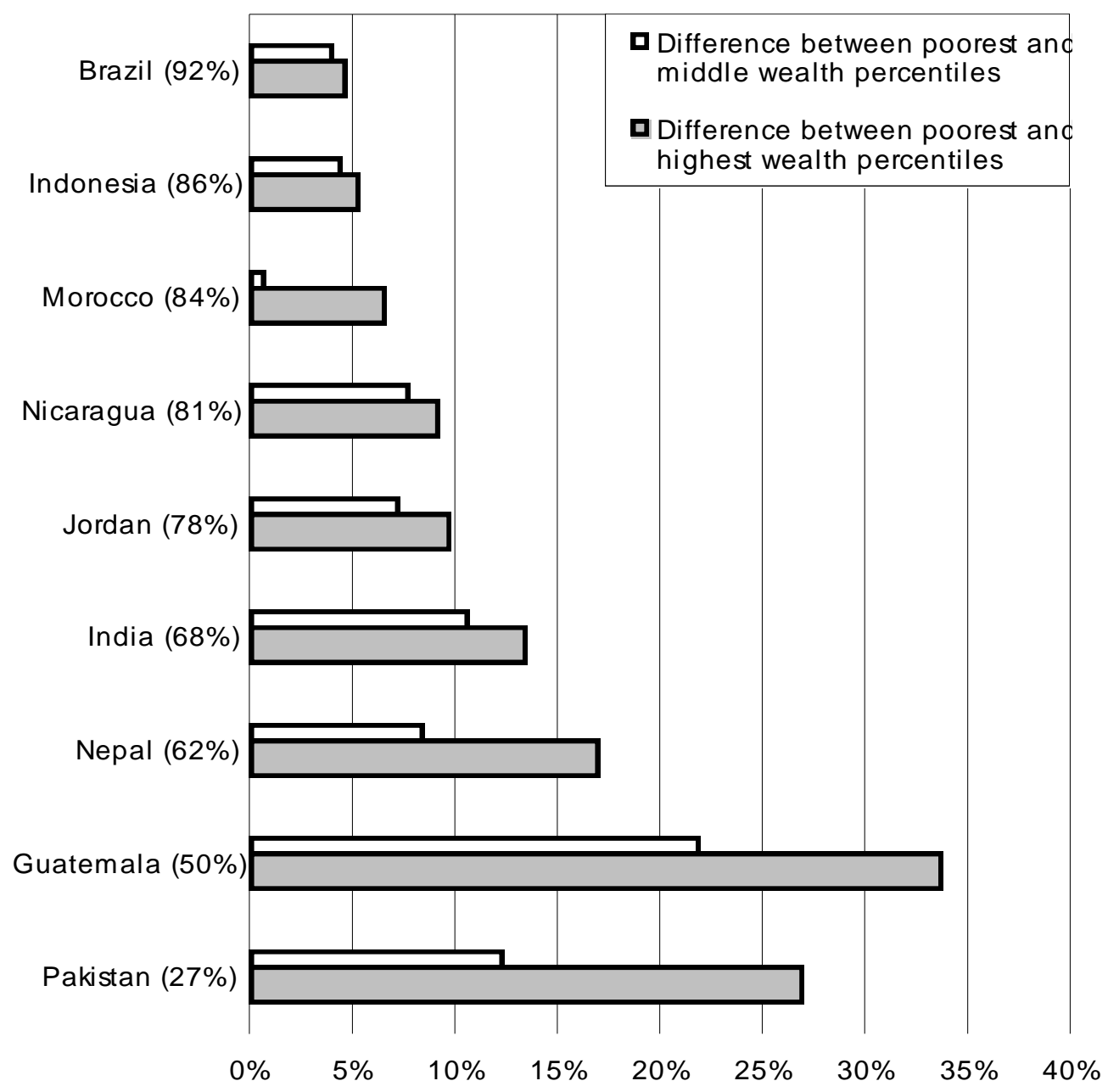

Notes: Adjusted differentials from logit regression analysis, differentials significant at .01 level. Countries are listed in descending order according to predicted percentage of households belonging to lowest wealth category, shown in parentheses. 
Figure 3. Intergenerational relationships of poverty, schooling, and fertility

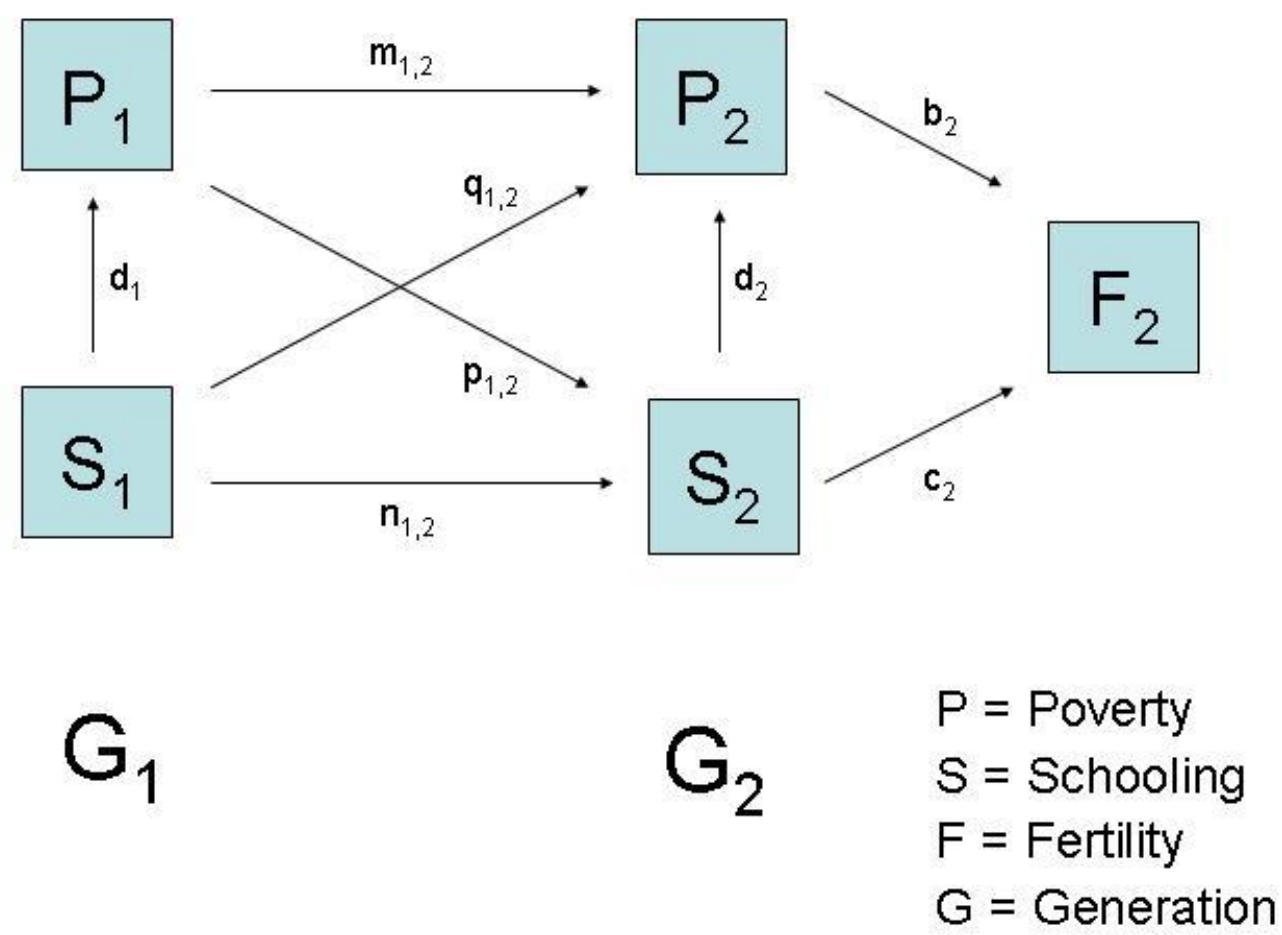


Figure 4. Percentage point difference in women wanting no more children between highest and lowest categories of education and wealth, currently married women

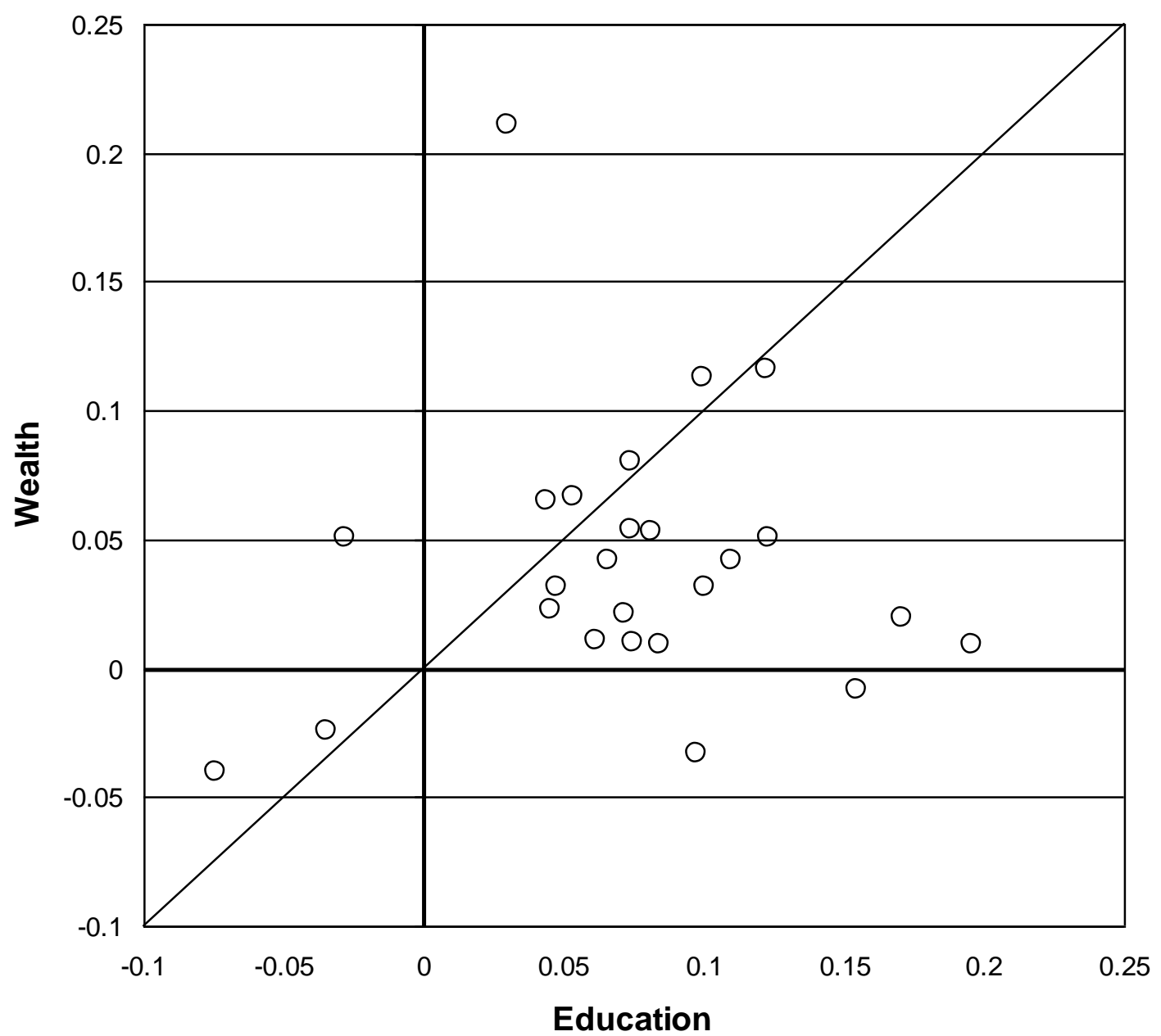

Note: Adjusted effects from logit regression analysis, effects significant at .01 level. 
Figure 5. Percentage point difference in contraceptive use among limiters between highest and lowest categories of education and wealth, currently married women

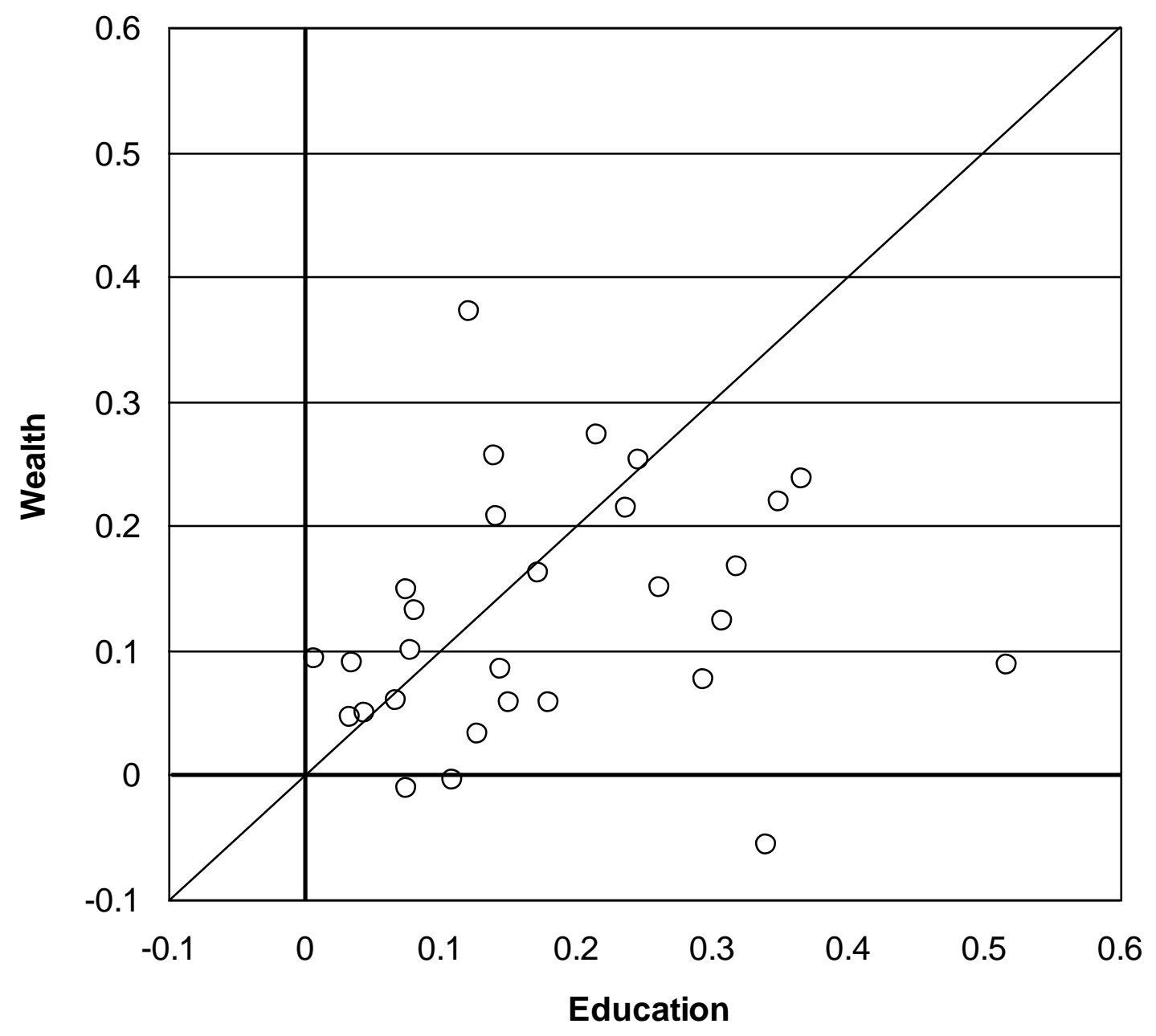

Note: Adjusted effects from logit regression analysis, effects significant at .01 level. 


\section{Poverty, Gender, and Youth Working Papers}

If still in print, single copies of up to three working papers from 1989 through 2003 are available free of charge.

Beginning with the 2004 issues, working papers are no longer available in print format. Instead they are distributed electronically. As each new paper is completed, subscribers are notified by e-mail and a link to the paper is provided.

To subscribe to the Poverty, Gender, and Youth working paper e-mail notification list, or to obtain back issues from 1989 to 2003, please send your request to pgywp@ popcouncil.org.

PDFs of recent issues are available at www.popcouncil.org/publications/wp/index.html

2007

4 Sajeda Amin, John B. Casterline, and Laura Spess, "Poverty and fertility:

Evidence and agenda."

3 Bussarawan Teerawichitchainan and James F. Phillips, "Ethnic differentials in parental health seeking for childhood illness in Vietnam."

2 Zachary Zimmer, Kim Korinek, John Knodel, and Napaporn Chayovan, "Support by migrants to their elderly parents in rural Cambodia and Thailand: A comparative study."

1 Sharon Ghuman and Cynthia B. Lloyd, "Teacher absence as a factor in gender inequalities in access to primary schooling in rural Pakistan."

\section{Policy Research Division working papers}

\section{6}

219 Cynthia B. Lloyd and Barbara S. Mensch, "Marriage and childbirth as factors in school exit: An analysis of DHS data from sub-Saharan Africa."
218 Ayaga A. Bawah, James F. Phillips, Martin Adjuik, Maya VaughanSmith, Bruce MacLeod, and Fred N. Binka, "The impact of immunization on the association between poverty and child survival: Evidence from Kassena-Nankana District of northern Ghana."

217 Zachary Zimmer, "Poverty, wealth inequality, and health among older adults in rural Cambodia."

216 John Bongaarts, "Late marriage and the HIV epidemic in sub-Saharan Africa."

215 John Bongaarts, "How long will we live?"

214 Zachary Zimmer, Toshiko Kaneda, and Laura Spess, "Urban versus rural mortality among older adults in China."

213 Paul Demeny and Geoffrey McNicoll, "The political demography of the world system, 2000-2050."

212 Monica Grant and Kelly Hallman, "Pregnancy-related school dropout and prior school performance in South Africa." 
211 Kelly Hallman, Sara Peracca, Jennifer Catino, and Marta Julia Ruiz, "Multiple disadvantages of Mayan females: The effect of gender, ethnicity, poverty, and residence on education in Guatemala."

210 Geoffrey McNicoll, "Policy lessons of the East Asian demographic transition."

209 Cynthia B. Lloyd, Cem Mete, and Monica J. Grant, "The implications of changing educational and family circumstances for children's grade progression in rural Pakistan: 19972004."

2005

208 James F. Phillips, Ayaga A. Bawah, and Fred N. Binka, "Accelerating reproductive and child health program development: The Navrongo Initiative in Ghana."

207 John Bongaarts and Griffith Feeney, "The quantum and tempo of lifecycle events."

206 Barbara S. Mensch, Monica J. Grant, and Ann K. Blanc, "The changing context of sexual initiation in subSaharan Africa."

205 Geoffrey McNicoll, "Population and sustainability."

204 John Bongaarts, "The causes of stalling fertility transitions."

203 Ayaga A. Bawah and Fred N. Binka, "How many years of life could be saved if malaria were eliminated from a hyperendemic area of northern Ghana?"

202 Barbara S. Mensch, Susheela Singh, and John B. Casterline, "Trends in the timing of first marriage among men and women in the developing world."
Zachary Zimmer, "Active life expectancy and functional limitations among older Cambodians: Results from a 2004 survey."

200 Brian Wells Pence, Philomena Nyarko, James F. Phillips, and Cornelius Debpuur, "The effect of community nurses and health volunteers on child mortality: The Navrongo Community Health and Family Planning Project."

199 Zachary Zimmer, Linda G. Martin, Mary Beth Ofstedal, and Yi-Li Chuang, "Education of adult children and mortality of their elderly parents in Taiwan."

198 Mian Bazle Hossain, James F. Phillips, and Thomas K. LeGrand, "The impact of childhood mortality on fertility in six rural thanas of Bangladesh."

197 Kristine R. Baker, Mary Beth Ofstedal, Zachary Zimmer, Zhe Tang, and Yi-Li Chuang, "Reciprocal effects of health and economic wellbeing among older adults in Taiwan and Beijing."

196 Mark R. Montgomery and Paul C. Hewett, "Poverty and children's schooling in urban and rural Senegal." 